\title{
Sistema suplementar de saúde e internação domiciliar de idosos na perspectiva da bioética crítica \\ Cláudio Andraos ${ }^{1}$, Cláudio Lorenzo ${ }^{2}$
}

\section{Resumo}

No Brasil, atualmente, a internação domiciliar (ID) é a principal opção para a desospitalização de idosos, sobretudo no sistema suplementar. Variados conflitos éticos surgem no contexto da assistência em meio a contextos familiares diversos. Neste trabalho, realizamos um estudo exploratório de dois casos de ID em operadora de planos de saúde, na qual os conflitos éticos identificados foram delimitados a dois campos principais de atuação da bioética: o da bioética clínica, no tocante às relações interpessoais e tomadas de decisão em torno da assistência, e o da bioética aplicada à saúde pública, no pertinente aos desafios para a organização e oferta de serviços. Os conflitos foram discutidos com base no modelo de bioética crítica. $\mathrm{O}$ estudo gerou proposições para a redução de alguns conflitos éticos envolvidos na ID e demonstrou a necessidade de pesquisas mais amplas para conhecer em maior extensão e profundidade este problema.

Palavras-chave: Bioética. Assistência domiciliar. Idoso. Saúde pública. Setor privado.

\section{Resumen}

Sistema de salud complementario y la atención a domicilio a los ancianos en la perspectiva de la bioética críticos

En Brasil, actualmente, la hospitalización domiciliar (ID) es la principal opción para disminuir la ocupación de los ancianos en el sistema adicional de salud. Surgen varios conflictos éticos para la asistencia en medio a diversos contextos familiares. En este trabajo, realizamos un estudio exploratorio de dos casos de ID en las operadoras de seguros de salud, en la cual los conflictos éticos identificados fueron delimitados a dos campos principales de actividad de la bioética: el de la bioética clínica referente a las relaciones interpersonales y en las decisiones en torno a la asistencia, y el de la bioética aplicada a la salud pública, respecto a los desafíos para la organización y prestación de los servicios. Los conflictos fueron discutidos en base en el modelo de bioética crítica. El estudio generó proposiciones para la reducción de algunos conflictos éticos involucrados en la ID, y fue demostrado la necesidad de investigaciones más amplias para conocer en mayor extensión y profundidad este problema.

Palabras-clave: Bioética. Asistencia domiciliar. Anciano. Salud pública. Sector privado.

\begin{abstract}
Supplementary health system and home care of the elderly in the perspective of critical bioethics

Home Care $(\mathrm{HC})$ is currently the main option in elderly dehospitalization, especially in the supplementary system. Varied ethical conflicts arise in the context of assistance along with varied familiar contexts. We performed an explanatory study of two HC cases in health insurance providers, in which the ethical conflicts were delimited in two main Bioethics playing fields: the clinical bioethics, regarding to interpersonal relationships and decision-making on assistance; and the Bioethics applied to public health, regarding to challenges to the organization and provision of services. The conflicts were discussed based on the critical bioethics model. The study generated propositions for reducing some ethical conflicts on $\mathrm{HC}$, and demonstrated the need of more extended studies in order to know in greater length and depth this problem in Brazil.
\end{abstract}

Key words: Bioethics. Home care. Elderly. Public health. Private sector.

Aprovação CEP/FS-UnB n 055/12

1. Mestre claudioandraos@gmail.com 2. Doutor claudiolorenzo.unb@gmail.com - Universidade de Brasília (UnB), Brasília/DF, Brasil.

Cláudio Andraos - SHCES, Quadra 501, bloco E, aptº 203, Cruzeiro Novo CEP 70650-515. Brasília/DF, Brasil. 
O fenômeno do envelhecimento populacional no Brasil tem-se acelerado nos últimos 20 anos, acompanhando o desenvolvimento do país, a redução da pobreza e algumas melhorias no acesso a bens e serviços de saúde. Os muito idosos (acima de 80 anos) têm sido considerados como o segmento populacional que mais cresce, representando, na atualidade, $12,9 \%$ da população idosa e $1,1 \%$ da população total ${ }^{1}$. As projeções do Instituto Brasileiro de Geografia e Estatística (IBGE) para 2050 são de que a população acima de 65 anos represente $22,71 \%$ do total ${ }^{2}$.

É consenso em saúde coletiva que este grupo etário é mais suscetível a doenças crônico-degenerativas ${ }^{3}$, acidentes por queda e a importantes fatores no incremento da morbimortalidade, liderando com $56,1 \%$ as internações por causas externas ${ }^{4}$. A vulnerabilidade específica deste grupo leva a maior utilização de serviços hospitalares em tratamentos de longa duração; significando, consequentemente, maiores custos de assistência ${ }^{5}$. Desse modo, o envelhecimento populacional representa, além de transição demográfica, uma transição epidemiológica, com claras implicações para a organização da atenção à saúde ${ }^{6}$.

No Brasil, a internação domiciliar (ID) tem sido um dos programas mais utilizados para a desospitalização do idoso e o mais amplamente recorrido pelo sistema de saúde suplementar. Veras e colaboradores ${ }^{7}$ demonstraram que as maiores coberturas proporcionais do sistema suplementar estão, exatamente, no grupo etário de idosos, sendo a modalidade de operadoras de autogestão a que tem a maior proporção de idosos na carteira, correspondendo a $28,2 \%$ do total de segurados.

O próprio Estado reconhece ainda não existir no país uma prática satisfatória de atenção à saúde do idoso ${ }^{8}$. Essa realidade acaba por tornar a família o lócus social quase exclusivo de cuidados aos idosos, o que caminha na direção contrária à realidade da vida cotidiana e ao contexto socioeconômico das famílias brasileiras na contemporaneidade, nas quais a maioria dos adultos trabalha fora e não existem condições financeiras para a contratação de cuidadores profissionais. Como demonstrado por Lima-Costa e colaboradores ${ }^{9}$, a maioria dos idosos no Brasil tem renda mensal inferior a um salário mínimo - da qual gasta um quarto com compra de medicamentos.

Diante deste contexto, os critérios para elegibilidade da ID deveriam considerar três aspectos: 1 ) circunstância individual do enfermo; 2) condições ambientais e; 3 ) características do grupo familiar ${ }^{10}$.
O primeiro aspecto relaciona-se com o estado clínico do idoso, grau de dependência funcional e situação socioeconômica. $O$ segundo, refere-se às condições do domicílio para a instalação dos equipamentos e acolhimento da equipe. $O$ terceiro, diz respeito ao tipo de atenção familiar que o idoso recebe e as possibilidades e disposição da família em participar dos cuidados.

Apesar da evidente necessidade de considerar esses aspectos frente à decisão pela ID, as operadoras de planos de saúde utilizam critérios eminentemente clínicos para produzir tanto o escore de elegibilidade para a internação domiciliar quanto para classificar o grau de complexidade requerido no planejamento da assistência ${ }^{11}$. Existirá então, em muitos casos, uma profunda divergência sobre como a família e o plano de saúde definem e compreendem as necessidades do idoso e a indicação de uma ID, descompasso que vem contribuindo para o já avançado processo de judicialização da saúde ${ }^{12}$. Além disso, as novas relações estabelecidas no interior do domicílio em torno da assistência ao idoso são, por suas características específicas, potencialmente geradoras de conflitos.

O objetivo do presente trabalho foi investigar, a partir de um estudo de caso, conflitos éticos envolvidos em dois casos de instalação de ID por operadora de autogestão; analisá-los sob a perspectiva da bioética crítica e, a partir desses resultados, apontar possíveis ações que contribuam para reduzi-los ou evitá-los, provendo, ainda, dados para a elaboração de pesquisas mais amplas sobre o problema.

\section{ID pelo sistema suplementar de saúde na pers- pectiva bioética}

O sistema suplementar de saúde é uma realidade no país e está previsto na própria organização do Sistema Único de Saúde (SUS). Segundo a Agência Nacional de Saúde Suplementar (ANS), o Brasil conta com 48,6 milhões de pessoas seguradas por um plano de saúde ${ }^{13}$, o que representa $25,1 \%$ da atual população, sendo este seguro proporcionado, predominantemente, pelos vínculos formais de trabalho ${ }^{14}$.

A ANS define como operadoras de saúde as empresas que comercializam planos de saúde. Esta classificação pode ser condensada em cinco modalidades: seguradoras e administradoras de saúde; medicina e odontologia de grupo; cooperativas médicas e odontológicas; entidades filantrópicas e autogestões em saúde ${ }^{15}$. A modalidade autogestão é definida como entidade ou parte de uma empresa 
que opera serviços de assistência ou é responsável pelo plano de saúde de seus próprios empregados, não tendo fins lucrativos. Hoje, essa modalidade é responsável por 5,2 milhões de segurados.

O fato de não ter fins lucrativos deveria, teoricamente, oferecer aos gestores dessa modalidade maior margem de manobra na oferta de serviços, vez que o balanço financeiro final só necessitaria manter o setor autossustentável, sem onerar outros setores. Entretanto, os desafios administrativos impostos pela limitação de expansão da clientela e o acúmulo contínuo de faixas etárias mais elevadas têm levado as autogestões a aplicar uma racionalidade baseada, sobretudo, na análise do custobenefício dos seus programas; orientada, quase exclusivamente, pela priorização das questões coletivas sobre as individuais, em consonância com o utilitarismo hegemônico em saúde coletiva, para situações nas quais há escassez de recursos. Costumam, portanto, utilizar os mesmos critérios para indicação da ID que as demais modalidades de operadoras com fins lucrativos.

Domicílios mais pobres em geral têm espaço mais restrito, predispondo a doenças respiratórias e apresentando menor possibilidade de adaptação aos limites de mobilidade do idoso, bem como propiciando mais risco de quedas. Adicionalmente, as condições socioeconômicas desfavoráveis também interferem nas relações interpessoais, reduzindo o tempo disponível para atenção aos idosos. Estudos têm demonstrado que mesmo diferenças mínimas na renda mensal per capita entre as famílias são suficientes para determinar aos idosos pior condição de saúde, maior dependência e menor mobilidade física ${ }^{16}$. Ademais, dados empíricos ainda não bem metodologicamente documentados registram a existência de famílias nas quais, independentemente da condição socioeconômica e da possibilidade de seus membros dispensarem cuidados, existe progressivo esvaziamento afetivo em relação ao idoso, motivo pelo qual essas famílias buscam simplesmente transferir para o nível profissional e para a dimensão institucional toda a responsabilidade com os cuidados requisitados. Nesses casos, também estão bastante reduzidas as possibilidades de cooperação mais estreita entre cuidadores informais (familiares) e formais (profissionais) ${ }^{17}$. Os significados que emergem das vivências familiares são particulares e específicos, donde a necessidade de conhecer e considerar essas singularidades no momento de prestar uma assistência domiciliar ${ }^{18}$.

A diversidade de contextos tem duas implicações diretas para uma abordagem bioética: interfere nas relações interpessoais em torno da assistência individual à saúde do idoso, provocando conflitos no campo da bioética clínica, e impacta o planejamento e execução da oferta de ID, remetendo o problema também ao campo da bioética aplicada à saúde pública ${ }^{19}$. Para dar conta da complexidade dos conflitos éticos gerados por esse problema um modelo teórico de bioética precisa considerar os jogos de interesse e poder em torno da prestação da atenção à saúde, interpretar as formas de racionalidade que elegem critérios e organizam as ofertas de serviço, e analisar influências das estruturas sociais e dados de contextos na geração dos conflitos interpessoais e interinstitucionais. Em seguida, produzir reflexões e proposições de ação dirigidas aos dois campos bioéticos envolvidos.

A América Latina tem se destacado na produção de modelos teóricos que privilegiam a análise de conflitos éticos na saúde decorrentes de práticas sociais de dominação; relações mercado-Estado, conflitos de interesse nas instituições etc., dirigindo suas proposições às reformas de sistemas de saúde que visem solucionar essas injustiças e estabelecendo relações estreitas com o cumprimento dos direitos humanos ${ }^{20-23}$. No Brasil, entre esses modelos os mais conhecidos são a bioética de proteção, inicialmente elaborada por Schramm e Kottow ${ }^{22}$ e posteriormente aperfeiçoada por este último, bem como a bioética de intervenção, de Garrafa e Porto ${ }^{24}$. A confluência de teorias e pensamentos bioéticos que trabalham nesta perspectiva tem recebido o título de bioética social ${ }^{25}$.

O presente estudo analisa o problema de pesquisa a partir de um modelo que se enquadre nesta perspectiva social, o da bioética crítica. Duas correntes desse modelo têm disputado espaço: uma, baseada na crítica das ciências sociais à bioética, formulada por autores como Renée Fox, Barry Hoffmaster e Charles Bosk, para os quais a bioética tem relegado fatores sociais e culturais a segundo plano e privilegiado teorias filosóficas idealizadas, propondo, a partir daí, que ela passe a produzir investigações empíricas para confrontar teorias com evidências ${ }^{26}$. E a segunda, melhor desenvolvida na América Latina, baseada na teoria crítica da Escola de Frankfurt, sobretudo na teoria do agir comunicativo de Habermas ${ }^{27,28}$. É ela que constitui nosso referencial teórico de análise. Uma descrição mais detalhada deste modelo extrapolaria os objetivos deste artigo, por isso vamos nos deter a definições e conceitos que contribuam para a discussão dos resultados.

A teoria crítica nasce de uma crítica à pretensa neutralidade científica, sobretudo quando atinge as 
ciências humanas e defende como objetivo principal a emancipação daqueles que foram vulnerados por uma estrutura social baseada na fusão entre Estado e capital, mercado e ciência. Nega, assim, uma abordagem neutra dos fenômenos sociais e propõe uma investigação das possibilidades de transformação das condições que propiciam a vulneração e a exploração de indivíduos e grupos. Desse modo, uma bioética fundamentada na teoria crítica toma os conflitos éticos, tanto no plano das relações interpessoais quanto no plano da tomada de decisão de impacto coletivo, como fatos socioculturais historicamente produzidos e sob incontornável influência política. A bioética deve buscar vias de resolução ou prevenção de conflitos em uma perspectiva que considere os limites impostos pelas circunstâncias específicas dos sujeitos envolvidos, sem se afastar das dimensões sociopolíticas mais amplas, que influenciam a geração e manutenção dos conflitos.

Nesta perspectiva, no contexto brasileiro, diferenças socioeconômicas tão marcadas entre as diversas famílias que condicionam disponibilidade de tempo para o cuidado dos seus idosos são tomadas como fatos sociais historicamente determinados, produto das próprias injustiças sobre as quais se consolidaram as estruturas sociais no país. Da mesma forma, a ausência do Estado na atenção à senilidade, impulsionando famílias a buscarem na ID uma solução para dispor de um cuidador diário, é também reflexo histórico de uma função do Estado que aceita e reproduz injustiças sociais. Para estudar estes fatos sociais três conceitos fundamentais para a bioética crítica são especialmente importantes: $r a-$ cionalidade instrumental, colonização do mundo da vida e racionalidade comunicativa.

Racionalidade instrumental é definida como uma forma de racionalidade dirigida a encontrar os melhores meios para o alcance de um determinado objetivo, sem considerar qualquer reflexão moral sobre a natureza e uso desses meios. As ações que dela derivam são sempre estratégicas. Segundo a teoria crítica, no capitalismo moderno essa forma de racionalidade se fundiu à racionalidade científica e se tornou a forma preferencial de racionalidade dos poderes econômicos, políticos e administrativos. De certa maneira, a utilização de critérios eminentemente clínicos pelas operadoras de planos de saúde para a elaboração e oferta de serviços de atenção domiciliar ao idoso está sustentada por uma racionalidade eminentemente instrumental.

Colonização do mundo da vida é a dimensão individual que emerge do encontro de três elementos formadores da subjetividade: personalidade, sociedade e cultura. Sua colonização seria a invasão desse mundo por valores que emergem dos poderes dominantes. O principal seria a colonização pela racionalidade instrumental, produzindo formas hegemônicas de interação social mediadas pelos interesses financeiros e burocracia administrativa, fazendo com que as relações interpessoais passem a ser dominadas por estratégias egoístas visando à realização pessoal. $O$ esvaziamento afetivo em relação aos idosos por membros de famílias de classes abastadas, por exemplo, pode ser resultado dessa colonização, vez que os idosos limitados aos seus domicílios não parecem capazes de contribuir com esses objetivos, e mais que isso, impõe obstáculos à realização plena.

Racionalidade comunicativa pretende ser a forma principal de oposição à racionalidade instrumental e a via pela qual se alcançará o planejamento de ações capazes de contribuir para a emancipação dos vulnerados e resolução ou prevenção dos conflitos morais ou políticos. Parte da premissa de que a única maneira legítima de reconhecer a validade de uma proposição qualquer, tenha ela uma intenção avaliativa ou prescritiva em relação às práticas sociais, é por meio da argumentação livre entre os diversos atores sociais envolvidos e pela aceitação racional da força dos argumentos. A comunicação é seu fundamento e os espaços democráticos de discussão criados no âmbito político ou institucional, tais como comitês de ética e bioética, a estrutura necessária a sua prática.

\section{Método}

Utilizamos nesta pesquisa o estudo de caso. Trata-se de método de pesquisa qualitativa definido como exploração investigatória de casos únicos ou múltiplos que formam um sistema bem delimitado no tempo e no espaço ${ }^{29}$. Trabalhamos com o modelo descrito por Yin ${ }^{30}$, segundo o qual os casos escoIhidos formam um sistema constituído por diversas fontes de informações e dados, tais como entrevistas, observação e análise documental, inseridos em um contexto socioeconômico e cultural específico que define em seu conjunto uma unidade de análise.

Para nossa pesquisa foram selecionados dois casos: caso $A$, no qual a ID foi indicada porque atendia aos critérios clínicos de elegibilidade; e caso $B$, em que a ID não atendia aos critérios e só foi concedida mediante cumprimento de liminar judicial. A unidade de análise foi formada por: 1 . Análise do dossiê médico dos idosos; 2 . Observação direta do 
domicílio e relações familiares; 3 . Entrevistas semiestruturadas com quatro atores envolvidos em cada um dos casos: idosos, cuidadores familiares, cuidadores profissionais e gestores da operadora.

Outros critérios para seleção dos casos foram: que os idosos envolvidos tivessem grau de autonomia suficiente para responder a entrevista e compreender os objetivos e desconfortos da pesquisa; que o cuidador profissional o estivesse acompanhando por um período igual ou superior a duas semanas; que o cuidador familiar fosse ao mesmo tempo o membro da família que assume a maior carga de responsabilidade e tomada de decisão no cuidado ao idoso, e que tivesse sido o solicitante da ID; que os gestores fossem aqueles diretamente responsáveis pela liberação ou negativa das ID.

A análise das entrevistas permitiu separar a identificação de conflitos éticos em duas categorias principais:

- Conflitos em torno da solicitação e Instalação da ID;

- Conflitos em torno da assistência direta ao idoso.

A pesquisa foi conduzida em total respeito às diretrizes e normas brasileiras sobre ética em pesquisa envolvendo seres humanos. Todos os entrevistados assinaram termos de consentimento livre e esclarecido e o protocolo da pesquisa aprovado pelo comitê de ética da Faculdade de Ciências da Saúde da UnB.

\section{Resultados e discussão}

\section{Caso A - ID atendia aos critérios clínicos}

Os dados de dossiê mostram tratar-se de um idoso de 73 anos, portador de enfisema pulmonar, diabetes mellitus, câncer de próstata e de laringe em remissão, que após complicações do diabetes teve longo internamento e apresentou escore clínico suficiente para indicação da ID. Vive há 27 anos com sua esposa (cuidadora familiar) de 53 anos e com um filho adulto jovem, recém-saído da adolescência, no entorno do Distrito Federal, cerca de 40 km de Brasília.

Habitam uma casa grande, arejada e com boas condições para instalação do serviço de internação domiciliar, sem prejudicar a circulação pelo cômodo. Havia uma mesa ao lado da cama, com um medidor de pressão arterial e um glicosímetro, além de um concentrador de oxigênio em uso ininterrupto. As relações entre o idoso e sua esposa mostravam sinais de carinho e atenção mútuos, com certa tendência a predomínio de autoridade por parte dela. O filho, em nenhum momento, participou dos contatos feitos com a família, parecendo assumir uma tendência a distanciar-se do problema.

\section{Conflitos em torno da solicitação e instalação da ID}

Segundo a esposa, o idoso passou mais de cem dias no hospital sem que ninguém tivesse comentado a possibilidade de ID até que finalmente, por uma fisioterapeuta, ela ficou sabendo da existência do serviço e de seu possível direito de requerê-lo. E assim descreve seu primeiro contato na operadora para solicitar a ID: "Eu fui até o plano de saúde e a menina [funcionária]: "Não! Não é bem assim não! Tem que ver se o paciente tá em condições de entrar no 'home care', que não sei o quê....". Após a obtenção de requisição para ID do médico assistente, a cuidadora familiar parece ter sido elevada a um patamar superior em relação à qualidade do acolhimento: "Eles me ouviram. Nossa! Assim, acho que eles olharam mais para mim, porque inicialmente eu estava tão assim, né? Muito desgastada...".

O primeiro problema moral aqui identificado relaciona-se com a deficiência de comunicação pelo hospital e operadora do plano, o que interfere na autonomia e no direito à saúde do paciente e sua família. Primeiro, houve falta de informação à família sobre a possibilidade de ID, o que pode ser resultado dos jogos de interesse em torno dos ganhos e gastos relacionados ao internamento hospitalar, ou da simples falta de programa de informação aos clientes pela operadora.

Segundo, a abordagem da funcionária da operadora no primeiro contato pareceu, antes de tudo, preocupada em apresentar as exigências do plano de saúde para a prestação do serviço do que compreender as demandas do cliente, o que podemos entender como uma colonização das interações sociais pelos elementos burocrático-administrativos. Essa deficiência comunicativa, além de representar um acolhimento deficiente, traz resultados negativos diretos sobre o bem-estar do paciente e seu familiar, aumentando o desgaste físico e psicológico, e ainda significando submissão a maiores riscos de infecções hospitalares ao idoso.

$\mathrm{Na}$ visão da gestora da operadora, o que aumenta as solicitações de ID é o processo de negação da doença por parte da família, o medo e as dificuldades dessa família em assumir ou compartilhar a responsabilidade dos cuidados: 
"A maioria das famílias não encara a doença do paciente, nega a doença do paciente. Como passam muito tempo hospitalizados, vendo o paciente cheio de dispositivos, sonda, cateter e respirador, eles acham que aquilo é um... monstro na frente dele... Tem dois lados, tem o lado do medo, tem o lado da negação da doença do paciente e tem aquela questão social que 'a gente tá pagando' a gente tem direito, então é a operadora que tem que cuidar do meu familiar mesmo, não sou eu... Não quer dividir essa responsabilidade..."

No discurso da cuidadora familiar foi possível perceber insegurança em lidar com os equipamentos: "Como é que eu vou ficar vendo negócio de glicemia, essas coisas? Eu não sei!". Isto é plenamente compreensível, vez que seu manuseio introduz nova realidade no cotidiano das famílias, para a qual não foram preparadas ${ }^{31}$. Mas em nenhum momento foi possível perceber negação da doença ou indisponibilidade em dividir responsabilidades. Em contrapartida, a importância da ID foi claramente reafirmada: "Se não fosse essa internação [ID] ele podia já ter ido pro hospital. Porque ele caiu duas vezes da hipoglicemia, ele desmaiou. Se não fosse a [ID] ele tinha morrido...".

A tendência à generalização por parte de gestores na compreensão das condutas familiares ante a ID pode ser especialmente promotora de conflito à medida que influencia a forma como a própria operadora lida com as solicitações e estabelece suas relações com os clientes em torno delas. Isso parece apontar para ausência de espaços de discussão entre gestores, profissionais de saúde e pacientes.

\section{Conflitos em torno da assistência direta ao idoso}

No caso em destaque, a esposa era o único membro da família responsável pelos cuidados ao idoso, ficando evidente o seu grau de desgaste: "Na realidade eu não tenho mais vida, né? Essa é que é a realidade. (...), eu não posso mais viajar, eu não posso mais me ausentar de casa. Mesmo que tenha uma técnica, (...) minha preocupação hoje, vinte e quatro horas, é ele". O idoso também demonstra reconhecer esse desgaste: "Mais encargo para a esposa, né? A vez que era no hospital ela tinha que me virar, pegar no colo, me botar na cadeira pro banho. (...) Coitada, pegava pesado, eu pesava mais de 80 quilos...".

Vale notar, entretanto, que a cuidadora familiar ameniza o não envolvimento do filho: "Ele é jovem, adolescente, e tá estudando, tá fazendo faculdade e procurando estágio, não tem tempo para ficar cuidando do pai". Fatores como sobrecarga de cuidadores familiares, certa tendência ao isolamento e abdicação das próprias necessidades já têm sido descritos na literatura em relação aos internamentos hospitalares prolongados ${ }^{17,18,32,33}$ e podem ser ainda mais graves na ID, por se tratar de uma condição sem prazo definido para acabar.

$\mathrm{Na}$ relação com as cuidadoras profissionais existe reconhecimento pelo valor do trabalho técnico desempenhado, mas a cuidadora familiar deixa claro o seu lugar de comando: "Como tenho uma personalidade assim... forte, eu chego e já falo o que eu quero: 'Ó, não gostei, não tá bom'. Porque você cria uma relação de amizade, mas antes de tudo, aqui é como se fosse patrão e empregado". O idoso demonstra reconhecer a importância dos dois tipos de cuidados, familiar e profissional: "Se tira um me falta o outro. Tirar o outro, vou sentir falta. Aqui dependo dos dois".

Três aspectos relacionados às relações interpessoais em torno da assistência merecem destaque: primeiro, deve ser considerado dever moral dos funcionários da operadora levarem em consideração o grau de desgaste dos cuidadores familiares no momento de estabelecerem relações com os mesmos, indicando inclusive apoio psicológico quando necessário; segundo, o fato da cuidadora familiar utilizar argumentos tipicamente de racionalidade instrumental, quando coloca a necessidade de estudo e formação profissional do filho, algo natural àquele momento da vida de todo jovem, como condição suficiente para justificar uma postura egoísta de distanciamento dos cuidados com o pai, demonstra que a colonização do mundo da vida pela racionalidade instrumental não é exclusiva dos profissionais de saúde e gestores institucionais; terceiro, a consideração da técnica de enfermagem pela cuidadora familiar como um tipo de empregado doméstico pode ser considerado reflexo das relações históricas de dominação de classes, que podem influenciar as relações e merecem esclarecimento no momento de instalar a ID.

Em relação ao respeito pela autonomia do idoso plenamente lúcido, como neste caso, o paciente afirma ter participação importante nas decisões: "Ah, entro na participação também. Principalmente na parte de terapia, né?" Entretanto, foi possível perceber que se tratava, em verdade, de uma autonomia tutelada. A cuidadora profissional relata sua conduta quando o idoso tenta modificar a forma ou momento de administração de medicamentos: "Às vezes ele acha que a medicação tem que ser de um jeito, que num tem que ser aquilo. Eu faço a medicação conforme tá prescrito. Conforme está na prescri- 
ção". Na cuidadora familiar percebeu-se um paternalismo autoritário ainda mais forte: "Geralmente sou eu mesma que dou a martelada final, sabe?"; "Eu vejo que ele é igual criança, ele depende totalmente de mim. Então, às vezes, eu brigo com ele, chamo a atenção, mas sempre pro bem-estar dele".

Mesmo considerando que podem existir algumas exigências terapêuticas rigorosas em termos de horários e formas de administração, muitas vezes é possível flexibilizá-los com margem de segurança. Aqui, o uso da racionalidade comunicativa poderia ajudar para, quando possível, garantir que pequenas modificações fossem acordadas, já que valorizam a autonomia do idoso e contribuem, consequentemente, para o seu bem-estar e autoestima. Da mesma forma, ainda que atitudes paternalistas sejam muito comuns e representem uma expressão de cuidado extremo nas relações de afeto, é importante que a família esteja esclarecida sobre a importância de valorizar as escolhas do idoso, vez que a cristalização de relação autoritária tem sido descrita como capaz de elevar a dependência emocional do idoso, reduzindo sua capacidade de autocuidado e gerando o risco de assumir comportamentos infantis em relação à saúde ${ }^{35}$.

A criação de espaços de discussão em grupo, onde familiares e profissionais pratiquem uma racionalidade comunicativa para troca de informações e experiências, poderia ser excelente meio para o planejamento conjunto de ações e suporte a todos os envolvidos.

\section{Caso B - ID obtida por liminar judicial}

Os dados de dossiê mostram tratar-se de uma idosa de 84 anos, portadora de insuficiência cardíaca (grau leve), mal de Parkinson (fase inicial) e hipertensão arterial controlada. Apresenta aspecto saudável, boa mobilidade, sem ajuda de bengala, e mostra certo dinamismo e participação no gerenciamento da casa. Seu domicílio, localizado a 45 quilômetros de Brasília, é pequeno, com cômodos estreitos, típico de classe média baixa. Observa-se um excesso de móveis para o tamanho dos cômodos, portais estreitos e pisos desnivelados, constituindo-se como ambiente com alto nível de risco para acidentes.

Não houve, neste caso, necessidade de instalação de mobiliário ou equipamento hospitalar. A idosa tem três filhos e mora com dois deles, também já idosos, sendo um aposentado e outro portador de esquizofrenia, estabilizada por medicamentos. $O$ relacionamento entre a idosa e esses filhos tem certo grau de formalidade e frieza, e fica claro que nenhum deles participa efetivamente nos cuidados com a mãe. 0 terceiro, com cerca de 50 anos, não mora na mesma casa, mas foi o que demonstrou maior envolvimento na prestação de cuidados e meIhor relacionamento com a mãe, sendo identificado como o cuidador familiar.

\section{Conflitos em torno da solicitação e instalação da ID} Neste caso, a ID foi solicitada por um familiar e não por um médico, vez que a idosa não se encontrava internada. Por esse motivo, a operadora sequer abriu processo para análise da elegibilidade da idosa e negou repetidamente a solicitação. A gestora confirma não existir meio formal para o atendimento de solicitação que parte diretamente da família: "Se for a pedido da família a gente descarta porque a gente tem os trâmites internos da autorização aqui, então eu não tenho nem como dar procedimento à abertura do processo". Isso demonstra um rigor burocrático para a abertura dos processos fundamentado em uma racionalidade exclusivamente instrumental com vistas à eficiência administrativa. Outro problema moral é que o "descarte" da solicitação não é sequer acompanhado por qualquer outro procedimento de apoio ao cliente e sua família.

Em paralelo, pela entrevista do cuidador familiar fica evidente o impasse vivido em função das profundas dificuldades para conciliar o trabalho, a família e os cuidados com a mãe. Reconhecia que não havia indicação para a ID, propriamente dita, mas reafirmava a necessidade de ter uma cuidadora profissional diariamente, acompanhando a idosa, o que estava fora de suas condições financeiras:

"Eu nunca levei chamada do chefe, tinha que tá toda hora pedindo, pedindo, pedindo, eu ficava constrangido, eu tenho a impressão que isto diminuiu muito a minha possibilidade de... de crescer no trabalho";

"Me atrapalhou muito aqui na familia, né? Porque eu tenho dois filhos, tenho minha mulher... às vezes eu tinha que escolher de quem eu ia cuidar naquele momento, minha mulher, meus dois filhos";

"Eu fui atrás de pesquisar preço e ver se eu tinha condição de manter cuidadores, mesmo sem aquela qualificação profissional, e nem isso eu tinha condições".

Um dos gestores entrevistados reconhece que faltam programas de assistência domiciliar de baixa complexidade, demonstrando sensibilidade para a distinção de demandas socialmente induzidas: 
"A razão clínica é a minoria dos casos, a grande maioria, em torno aí de uns setenta e cinco por cento, oitenta por cento, procura na tentativa de ter um cuidador e não uma assistência integral";

"A questão social, ela é muito nas classes, digamos assim... menos favorecidas financeiramente, a classe média e a abastada ela procura pra transferir a responsabilidade do cuidado para o convênio. Essa é a verdade".

Apesar deste reconhecimento por parte de altos funcionários da operadora, vale destacar que isso não tem sido suficiente para mobilizar a gestão, no intuito de estudar a viabilidade de novas modalidades de assistência domiciliar diária, não propriamente uma ID, que pudessem resultar, inclusive, em redução do número de internamentos hospitalares provocados por instabilidades e complicações de morbidades já existentes ou pela ocorrência de acidentes como queda, comuns em idosos que recebem cuidados insuficientes. Na saúde pública, a identificação de uma demanda importante implica no dever moral de envidar esforços no sentido de programar ações que respondam à mesma.

Pelos relatos do cuidador familiar vê-se que a forma como funcionários da operadora comunicaram ao familiar a impossibilidade de atender a demanda contribuiu para provocar alto nível de conflito interpessoal, que culminou na judicialização da demanda:

"A médica auditora falou: não. É obrigação sua! (...), ela foi grosseira comigo, eu reagi, fui grosseiro com ela";

"Uma gerente foi curta e grossa comigo: não, não fazemos, isso é problema seu! Usou termos assim mesmo, eu falei assim: é porque não é sua mãe! Nossa, essa menina ficou braba comigo! Falou: claro que não! Ainda bem que não é com minha mãe, que tem que passar por isso. Eu falei: ah, a sua mãe você não quer que passe por isso, agora o assistido do plano você quer que passe, né? Aí a conversa encerrou, eu tive que sair da sala dela...".

Pode-se notar claro problema moral na forma como esse acolhimento foi realizado, pois há desrespeito ao cliente, que se origina no não reconhecimento do outro e na indisponibilidade para se sensibilizar com suas necessidades, demonstrando despreparo para lidar com situações conflitantes e para estabelecer processo comunicativo capaz de levar ao entendimento, mesmo ante os limites impostos ao atendimento das demandas. A racionalidade é tipicamente instrumental: se o caso não se enquadra nos meus critérios clínicos cientificamente elaborados, então: "a obrigação é sua", "o problema é seu", o que na verdade constitui não forma equivocada de acolhimento, mas recusa do acolhimento, postura injustificável para qualquer empresa que se pretende responsável pelo bem-estar dos segurados.

O impacto da obtenção por liminar judicial da ID (mesmo que limitado apenas à presença de uma cuidadora profissional) sobre o bem-estar do idoso e da família foi sempre evidente no relato do cuidador familiar: "Aquele cuidado diário, que é típico de um cuidador, (...) [dá] condições de eu poder continuar trabalhando e sustentando, porque hoje, mesmo com home care, eu gasto em torno de quase um terço do meu salário pra manter minha mãe viva". Este fato reafirma a importância de estudar e implementar a oferta de novas modalidades de assistência domiciliar de baixa complexidade, e da elaboração de novos critérios que levem em conta as reais condições sociais da família e o grau de riscos aos quais os idosos estão submetidos por razões sociais implicadas em seus cuidados.

\section{Conflitos em torno da assistência direta ao idoso}

Do ponto de vista dos relatos, este caso foi bem menos marcante em conflitos relacionados à assistência individual ao idoso. Talvez o fato de o serviço ter sido implementado, mediante liminar, tenha inibido o relato de problemas interpessoais relacionados à assistência, no sentido de proteger o serviço obtido. Não foram descritas relações conflituosas entre o cuidador profissional e a idosa.

A cuidadora profissional descreve como "boa" a relação estabelecida com a idosa. Mas é possível perceber que o grau elevado de autonomia da idosa e sua insistência em tentar conduzir detalhes de seu tratamento ou de seu próprio comportamento são compreendidos como teimosia: "ela é uma ótima paciente, às vezes... um pouco teimosa" - o que pode demonstrar tendência à infantilização do idoso, encontrada também no Caso $A$.

Quanto aos benefícios da ID, a idosa parece compreendê-los antes dirigidos à sua condição de solidão que propriamente de saúde: "...eu tô achando bom. Eu tenho companhia, né?" E deixa entrever a ausência dos filhos. A cuidadora profissional também demonstra perceber a distância entre a idosa e os filhos que coabitam o domicílio: "Porque geralmente os filhos dela saem muito (...) tem que ter alguém que... conheça bem ela". 
Diversos autores já demonstraram que, além de reduzir riscos de complicações e acidentes, a companhia aos idosos é tanto terapêutica quanto preventiva em relação à depressão e a perda cognitiva que a solidão pode causar em idade avançada ${ }^{33}$. Desse modo, um serviço, mesmo de baixa complexidade, não pode ser considerado benefício menor ao estado de saúde de um idoso. Tal constatação reforça, mais uma vez, a necessidade de repensar os critérios que facultam a ID, para que possam suprir as necessidades de cuidados dos idosos de maneira ampla, condizente com os direitos humanos, com promoção à saúde e à qualidade de vida.

Foi também possível perceber, em relação às possibilidades de cuidado da família, que havia constrangimento, quase um obstáculo, no acompanhamento da idosa ao banho, uso do vaso sanitário ou ajuda nas trocas de roupa. Mesmo o filho, definido como cuidador familiar, parece ter isso claro: "Esse cuidado assim diário, realmente tem que ser com as meninas". A literatura registra que, independentemente do sexo do idoso sob cuidados, existe predomínio do gênero feminino nas tarefas relacionadas aos seus cuidados, representado especialmente por filhas, noras e esposas, como cuidadoras familiares ${ }^{34,35}$.

A designação de tal atribuição sofre, evidentemente, influência da determinação cultural dos papéis sociais dos gêneros, mas também refletem relações de dominação entre gêneros que contribuem para maior sobrecarga do gênero feminino. Temas que poderiam ser abordados, com vistas à sua transformação em espaços democráticos de discussão promovidos pelas operadoras de planos.

\section{Considerações finais}

Os dois casos aqui apresentados e discutidos apresentam conflitos que podem surgir em torno da internação domiciliar de idosos, tanto na dimensão individual da assistência, relacionados à bioética clínica, quanto na dimensão da organização e oferta de serviços de saúde, relacionados à bioética aplicada à saúde pública.

Ainda que a oferta de ID, em praticamente todas as categorias de operadoras em saúde suplementar no Brasil, tenha características bastante semeIhantes e siga os mesmos critérios eminentemente clínicos para indicação, o presente trabalho, por ser estudo de caso exploratório, tem limitado poder de generalização, necessitando de abordagens mais extensas e aprofundadas para identificar maior variedade de conflitos morais em ID e, consequentemente, propor formas mais amplas de preveni-los, reduzi-los ou solucioná-los.

Entretanto, a combinação da metodologia de estudo de caso, com uma reflexão baseada na bioética crítica, sobre os déficits comunicacionais nas relações interpessoais e a influência da variedade dos contextos socioeconômicos e das formas de vida cotidiana das famílias sobre as práticas domiciliares de saúde permitiu apontar algumas vias de solução para os conflitos identificados, tais como: necessidade de desenvolver programa de informação e comunicação à clientela sobre ID desde o momento do internamento hospitalar; oferta de modalidade de assistência domiciliar intermediária, baseada na presença do cuidador profissional em tempo parcial; desenvolvimento de programas de capacitação profissional e educação continuada para preparação do acolhimento, sobretudo em situações de divergência; oferta de serviços de suporte psicológico à família; criação de espaços de discussão para troca de experiências e informações entre profissionais, idosos e familiares envolvidos em assistência domiciliar.

Pode-se argumentar que a geração de demandas para modalidades de assistência domiciliar de baixa complexidade, quando não atendem aos critérios clínicos de ID utilizados pelo sistema suplementar de saúde, é causada pelo fato de o Estado brasileiro, mesmo contando com uma política nacional de atenção à saúde do idoso ${ }^{8}$, não desenvolver eficientemente ações programáticas na direção de cuidados especiais com o envelhecimento da população. Porém, pode-se também contra-argumentar que enquanto sistema suplementar as diversas modalidades de operadoras de plano de saúde tomam para si a responsabilidade de cuidar da saúde daqueles que vincula. Isso significa compromisso ético com o bem-estar dos seus vinculados e a utilização de um conceito amplo de saúde na elaboração de seus programas ${ }^{7}$.

Para um país que dentro de 37 anos espera ter uma população em torno de 215 milhões de habitantes, dos quais cerca de 49,4 milhões terão mais de 65 anos ${ }^{2}$, a programação e oferta de serviços de assistência aos idosos, bem como a prevenção e reduções dos conflitos éticos que delas possam advir, tornamse prementes e fundamentais. Esperamos com este trabalho ter conseguido estimular a necessária discussão sobre o assunto. 
Trabalho produzido no âmbito do Programa de pós-graduação em Bioética, Cátedra Unesco de Bioética/ Faculdade de Ciências da Saúde, Universidade de Brasília (UnB).

\section{Referências}

1. Brasil. Ministério da Saúde. Envelhecimento e saúde da pessoa idosa. Brasília: Secretaria de Atenção à Saúde; 2007.

2. Instituto Brasileiro de Geografia e Estatística. Projeção da população no Brasil por sexo e idade 1980-2050: revisão 2008. [Internet]. Rio de Janeiro: IBGE; 2008 (acesso 27 jan. 2013). (Estudos e pesquisas. Informação Demográfica e Socioeconômica; $n^{\circ}$ 24). Disponível: http://www.ibge.gov. br/home/estatistica/populacao/projecao_da_populacao/2008/projecao.pdf

3. Alvarenga MRM, Mendes MMR. O perfil das readmissões de idosos num hospital geral de Marília/ SP. Rev Latinoam Enferm. 2003;11(3):305-11.

4. Gawryszwski VP, Jorge MHPM, Koizumi MS. Mortes e internações por causas externas entre os idosos no Brasil: o desafio de integrar a saúde coletiva e atenção individual. Rev. Assoc. Méd. Bras. 2004; 50(1): 97-103.

5. Coelho Filho JM. Modelos de serviços hospitalares para casos agudos em idosos. Rev. Saúde Pública. 2000;34(6): 666-71.

6. Chaimowicz F. A saúde dos idosos brasileiros às vésperas do século XXI: problemas, projeções e alternativas. Rev Saúde Pública. 1997;31(2):184-200.

7. Veras RP, Caldas CP, Araújo DV, Kushnir R, Mendes W. Características demográficas dos idosos vinculados ao sistema suplementar de saúde no Brasil. Rev Saúde Pública. 2008;42(3):497-502.

8. Brasil. Ministério da Saúde. Portaria n².528, de 19 de outubro de 2006. Aprova a Política Nacional de Saúde da Pessoa Idosa. [Internet]. 2006 (acesso 25 jul. 2012). Disponível: http://portal.saude. gov.br/portal/arquivos/pdf/2528\%20aprova\%20a\%20politica\%20nacional\%20de\%20saude\%20 da\%20pessoa\%20idosa.pdf

9. Lima-Costa MF, Barreto S, Giatti L, Uchoa E. Desigualdade social e saúde entre idosos brasileiros: um estudo baseado na Pesquisa Nacional por Amostra de Domicílios. Cad Saúde Pública. 2003;19(3):745-57.

10. Barros SRTP, Braz MG, Cruz ICF. Pós-graduação em home care: uma exigência pela qualidade parte I. Revista Brasileira de Home Care. 1999;3(1):34-6.

11. Dal Ben LWD, Gaidiznski RR. Sistema de classificação de pacientes em assistência domiciliária. Acta Paul Enferm. [Internet]. 2006 (acesso 9 out. 2010);19(1):100-8. Disponível: http://www. scielo.br/pdf/ape/v19n1/a16v19n1.pdf

12. Ventura M, Simas L, Pepe VLE, Schramm FR. Judicialização da saúde, acesso à justiça e a efetividade do direito à saúde. Physis. 2010;20(1):77-100.

13. Agência Nacional de Saúde Suplementar. ANS Tabnet: informações em saúde suplementar. [Internet]. 2004 (acesso 20 fev. 2013). Disponível: http://www.ans.gov.br/anstabnet/tabcgi. exe?anstabnet/dados/TABNET_BR.DEF

14. Agência Nacional de Saúde Suplementar. Foco saúde suplementar. Jun. 2012 (acesso 5 dez. 2012). Disponível: http://www.ans.gov.br/images/stories/Materiais_para_pesquisa/Perfil_setor/ Foco/20120816_web_foco_junho_2012.pdf

15. Agência Nacional de Saúde Suplementar. Resolução RDC n 39, de 27 de outubro de 2000. Dispõe sobre a definição, a segmentação e a classificação das operadoras de planos de assistência à saúde. (acesso 3 nov. 2010). Disponível: http://www.ans.gov.br/texto_lei.php?id=380

16. Lima-Costa MF, Loyola Filho Al, Matos D. Tendências nas condições de saúde e uso de serviços de saúde entre idosos brasileiros: um estudo baseado na Pesquisa Nacional por Amostra de Domicílios (1998 - 2003). Cad Saúde Pública. 2007;23(10):2.467-78.

17. Schwanke CHA, Feijó AGS. Cuidando de cuidadores de idosos. Bioética. 2006;14(1):83-92.

18. Sena RR, Leite JCA, Costa FM, Santos FCO, Gonzaga RL. O cuidado no domicílio: um desafio em construção. Cogitare Enferm. 1999;4(2):58-62.

19. Fortes PAC, Zoboli ELCP. Bioética e saúde pública. São Paulo: Loyola; 2009.

20. Correa FJL. Fundamentos y princípios de bioética clínica, institucional y social. Acta Bioéth. 2009;15(1):70-8.

21. Porto D, Garrafa V. Bioética de intervenção: considerações sobre a economia de mercado. Bioética. 2005;13(1):111-23.

22. Schramm FR. Bioética da proteção: ferramenta válida para enfrentar problemas morais na era da globalização. Rev. bioét.(Impr.). 2008;16(1):11-23.

23. Albuquerque AAS. Bioética e direitos humanos. Rio de Janeiro: Loyola; 2011.

24. Garrafa V, Porto D. Intervention bioethics: a proposal for peripheral countries in a context of power and injustic. Bioethics. 2003; 17(5-6):399-416.

25. Correa FJL. Principios para una bioética social. Revista Bioétikos. 2009;3(1):18-25.

26. Hedgecoe AM. Critical bioethics: beyond the social science critique of applied ethics. Bioethics. 2004;18(2):120-43. 
27. Hoyos G. Estructuración del discurso bioético: comunicación y lenguaje. In: Garrafa V, Kottow M, Saada A, organizadores. Estatuto epistemológico de la bioética. México: Universidad Nacional Autónoma de México/Unesco; 2005. p. 193-219.

28. Lorenzo C. Teoria crítica e bioética: um exercício de fundamentação. In: Porto D, Garrafa V, Martins GZ, Barbosa SN, organizadores. Bioética, poderes e injustiças. Brasília: CFM; 2012. p. 171-88.

29. Creswell JW. Qualitative inquiry and research design: choosing among five traditions. Thousand Oaks: Sage; 1998.

30. Yin RK. Estudo de caso: planejamento e métodos. $4^{\mathrm{a}}$ ed. Porto Alegre: Bookman; 2010.

31. Ciosak SI, Braz E, Costa MFBN, Gonçalves N, Nakano R, Rodrigues J et al. Senescência e senilidade: novo paradigma na atenção básica de saúde. Rev Esc Enferm USP. [Internet]. 2011(acesso 22 jan. 2013);45(spe2):1.763-8. Disponível: http://www.scielo.br/scielo.php?pid=S0080$62342011000800022 \&$ script $=$ sci_arttext

32. Garbin CAS, Sumida DH, Moimaz SAS, Prado RL, Silva MM. O envelhecimento na perspectiva do cuidador de idosos. Ciênc Saúde Coletiva. 2010;15(6):2.941-8.

33. Saad A. Prólogo. In: Tealdi JC. Diccionario latino-americano de bioética. [Internet]. Bogotá: Unesco/Universidad Nacional de Colombia; 2008 (acesso 10 jan. 2013). Disponível: http://www. unesco.org.uy/shs/fileadmin/templates/shs/archivos/DicoPartel.pdf

34. Almeida L, Azevedo RCS, Reiners AAO, Sudre MRS. Cuidado realizado pelo cuidador familiar ao idoso dependente, em domicílio, no contexto da estratégia de saúde da família. Texto \& Contexto Enferm. [Internet]. 2012 (acesso jan. 2013);21(3):543-8.

35. Fernandes MGM, Garcia TR. Determinantes da tensão do cuidador familiar de idosos dependentes. Rev Bras Enferm. [Internet]. 2009 (acesso 25 jan. 2013);62(1):57-63. Disponível: http://www.scielo.br/scielo.php?script=sci_arttext\&pid=S0034-71672009000100009\&lng=en

\section{Participação dos autores}

Cláudio Andraos concebeu o artigo, conduziu os procedimentos de pesquisa e análise dos dados, realizou a revisão bibliográfica e participou da redação. Cláudio Lorenzo participou na definição da metodologia e na análise dos dados, contribuiu com a revisão bibliográfica e deu o formato final à redação.

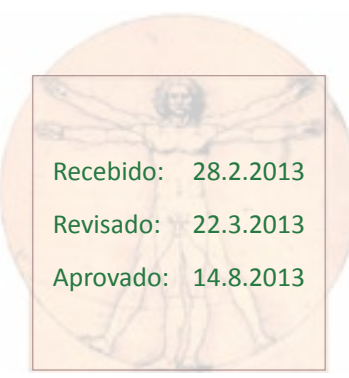

